\title{
Theoretical Framework of Computer Cognition for Use in Urban Design Process
}

\author{
Marko Lazić*, Ana Perišić, Predrag Šidjanin \\ Faculty of Technical Science, University of Novi Sad, Serbia
}

Citation: Lazić M, Perišić A, Šidjanin P. Theoretical Framework of Computer Cognition for Use in Urban Design Process. SEE Archit Des. 2015 Dec 30, 2015:10010. http://dx.doi.org

Key words: cognition; urban design; representation methods. Correspondence: Marko Lazić. Faculty of Technical Science, University of Novi Sad, Serbia. E-mail: lazic.m@uns.ac.rs Received: 12-Nov-2015; Revised: 29-Nov-2015; Accepted: 15-Dec-2015; Published: 30-Dec-2015

Copyright: ๑ 2015 Marko Lazić, Ana Perišić, Predrag Sidjanin. This is an open-access article distributed under the permits unrestricted use distribution, and reproduction in any medium, provided the original author and source are credited. Competing Interests: The author have declared that no competing interests exist.

\section{Abstract}

AIM: The purpose of this paper is to highlight a new paradigm in the urban design practice, assigning a pos sible role to computer cognition in architecture.

MATERIAL AND METHODS: Computer cognition is a synthesis of theories of cognitive science and the latest artificial intelligence-based computer principles. First, the development of computer systems used in architecture and urban design has been examined with the emphasis that one of the most important representations of urban systems is based on the cognitive aspect of urban environment.

RESULTS: Thus, the relationship between urban environment and cognitive science and computer science has been established. A framework of the implementation of computer technology into the urban design process has also been created.

CONCLUSIONS: Through the research framework of the new urban design tool - named DesignTool - the paper presents the initial theoretical postulates concerning the urban environment from the aspect of cognitive perception and their genesis.

\section{Introduction}

In present architectural, urban and planning practice, the role of information technology has become increasingly important. The use of computer models in architecture and urban planning dates back to the early $1950 \mathrm{~s}$. The early architectural drawing has undergone certain transformation by the introduction of computer - aided design software packages (CAD), as the widespread AutoCAD, ArchiCAD or other products available at the market. The breakthrough of computer applications in urban planning was marked by the use of municipal information systems, transportation system's modeling and land use programs. In recent decades, important visualization and representation tools have been developed, particularly within the framework of geographic information systems (GIS). With the development of GIS technology, it is likely to connect $2 \mathrm{D}$ and $3 \mathrm{D}$ spatial data by the use of software packages like
Arclnfo, ArcView or MapInfo, which are common tools of urban planners used in urban planning and related disciplines. On the other hand, for many years, urban design has almost been neglected in the development of computer systems. Nowadays, this situation is slowly changing.

\section{The development of computer systems in urban design}

Urban design is a discipline placed between architecture and urban planning - a discipline dealing with both architectural objects and blocks of buildings, with streets and landscapes. Urban design is an operational arrangement in the urban planning process which according to Barnet [1], provides urban growth, conservation and change with physically designed guidelines. 
Urban design is a part of activities of urban planning and arrangement of appropriate relationships between objects, infrastructure, landscape and the like. In urban design, all the technical, economic, social and aesthetic factors are involved, highly harmonized and mutually synthesized.

According to Batty, et al. (1998), urban design is almost neglected in the process of computerization. Since the late 1950s, both architecture and urban planning have been actively involved in software development, which simultaneously followed the developments in the electronics industry - both computer and satellite. CAD systems have dramatically and fundamentally changed the daily practice and organization of architectural offices. This made architectural practice much more efficient. New opportunities in the field of realistic 3D and real-time visualization like immersive virtual reality [2], have additionally changed the perspective of development of the architectural and planning profession. Furthermore, the architectural profession and its cooperation with participants at all stages of project design and construction (including maintenance) have been enhanced by the rapid development of BIM (Building Information Model) technology [3]. From the early 1960s, Geographic Information Systems (GIS) have completely changed the field of urban planning through the incorporation of satellite-collected spatial data, accurately constructing a broad spatial environment, or even the entire world (Google Earth, for example - an all available Internet application), with $2 \mathrm{D}$ or $3 \mathrm{D}$ components satisfying a wide scope of interests and professional needs.

The development of urban design software is disregarded, being almost unavailable in an appropriate form, as it is the case with architectural and urban planning software. There are several reasons for this 'software vacuum': the main one is in diversity of the urban design process and its large amount of participants with strong political influence, which cannot be software-processed. Another possible reason is the difficulty to synthesize the urban design methods with visualization techniques, which is now successfully completed through the connection between the CAD and GIS.

Within the GIS framework, several research efforts have been undertaken in urban design development for sketch planning, visualization and analyses that include GIS functionalities and multimedia visualization [4-8]. Some of the reaserches are focused on resolving issue of public participation in planning using utilitized graphical interface $[9,10]$. Most of these researches are intended to assist the urban design process in its various stages, rather than the implementation of urban design itself. Some decision-making assistance systems have been developed to assist planning for specific purposes, such as locating facilities and installations, or retails and the like [11-13].
The creative aspect of urban design has not been implemented in the development of computer applications; however, some basic supplementary tools are under development for the CAD, GIS and the Internet.

\section{Urban design-related problems}

There are several possible questions that may indicate some of the problems related to urban design. Some of the most important ones are the following: How to present the functional model of urban environment effectively? How to test the proposed solutions and how to choose the best? How to get the feedback of interested citizens? How to prepare the analysis of potential impacts and consequences? How to integrate all information with the new functional and conceptual model? How to make decisions based on experts and 'non-experts' (layman) democratic voting? How to implement the selected model? Modification of these issues to the level of computer technology may look as follows: Is it possible to create computer tools that integrate the analyses, appearances, shapes, shape changes, tests and decision making - all based on expert knowledge and the existing technologies, such as the CAD, GIS or the Internet, and which can be applied by both professionals and citizens? This single question can be replaced by hundreds of related questions, but there could be only few answers. The theoretical basis for the development of computer tools is briefly discussed below, contributing thereby only partially to the elimination of the urban design software-related vacuum.

Urban design manipulates at small scales, and it is less abstract than urban planning that operates at large scales. Urban design provides people with a clear picture of how design will look like. The potential of inclusion of new technologies in urban design is huge at the level of assistance at the neighborhood scale, both for specialists and for ordinary citizens. The large amount of different data, presented in a visual and acceptable form for all interested groups, can play a useful feedback in urban design. Due to be efficient and as collaborative as possible, designers need to determine the project framework that provides physical environment for users with the ability to directly participate in the project through the Internet. Results of public participation would be analyzed and included into the urban design creating process. This kind of 'reflective design' is an approach that will probably solve the problem of design by obtaining acceptable plans for urban systems [14]. 


\section{Representation of urban systems}

At the level of urban design, urban systems consist of four types of representation according to Batty, et al. [15]:

1) socio-economic information are traditionally spatial, macro information that are normally related to the area;

2) functional information relate to the relationships among the system's spatial elements;

3) 'acting' information are usually information reflecting several micro information, e.g. the way users react to imagery of the urban environment; and

4) physical information is geometric (vectored) in contrast to geographic (raster) information.

All these types of information are stored in different data banks, mostly GIS's. The representation of an urban system and the process design are perhaps best integrated through the relevance of GIS. Urban design consists of a small scale problem requiring $2 \mathrm{D}$ or $3 \mathrm{D}$ considerations. Urban design also includes a wide scope of interests, ranging from socioeconomic through functional, aesthetic, structural and others. The designer should control and be responsible for all these. In such circumstances it is necessary to have a good design tool at disposal, based on the latest development technologies, such as CityEngine, which is based on work of Parish and Mueller [16].

One of the four most important representations of urban systems is certainly the one that is based on cognitive aspect of the urban environment.

\section{Cognitive representation in urban design}

The idea of cognitive representation is defined by the way people understand and perceive the space around them. Cognitive representation in urban design is based on the concept of cognitive mapping, path-finding and navigation. Cognitive mapping is the relationship between the physical environment and psychological pattern of the related memorized information. As a cognitive approach to urban design, this research is based on the theory of urban design and the theory of computer cognition. The theory of urban design, as well as the concept of cognitive mapping, is taken from Kevin Lynch [17]. Path-finding and navigation are other aspect of integration of cognitive representation adopted for the present research.
Cognitive representation of urban design tends to be realistic both from cognitive aspects and the aspects of its implementation.

\section{Computer implementation into the urban design}

Batty, et al. (1998) suggests a framework for the development of computer techniques that can be applied in urban design. This framework illustrates the stages of implementation of new computer technologies into the process of urban design. This framework consists of three main parts:

1) data representation - showing the four types of representation of urban systems (socioeconomic, functional, 'performing' and physical);

2) models and systems represented by CAD models, functional models, economic models; and

3) urban design process, presented in various steps in the process, from problem defining to decision making regarding the best plan (implementation).

Data representation and models and systems correlate with 'GIS tools' that are also related with networks, photos, CAD, syntaxes, maps, graphic editors, and $2 D$ and $3 D$ models. When respecting certain criteria, this schematic framework can be universal. For the cognitive representation approach in the present study, the following components can be implemented into this framework: psychological recategorization, technical support, DesignTool and cognitive model. Batty's universal framework has been adopted, modified and minimized in order to meet the needs of cognitive approach to this specific research [18].

The proposed framework of implementation of computer technology into the urban design process in relation to the cognitive approach of this study consists of five parts (see Figure 1):

1) data representation indicates the relevant types of representation which are dominated by 'behavior' and 'psychological recategorization' (new type);

2) models and systems indicate the relevant models such as 'functional models' and 'cognitive models';

3) technical support is the framework of the existing computer techniques that can be used in urban design, such as the CAD, GIS or the Internet; 
4) DesignTool or designer's tool, is a new software application that can improve the urban design practice, and it is also the result of the present research; and

5) urban design process is a schematic representation of the process from indication of design problem through implementation of the DesignTool, and reaching alternative design solutions to implementation of the selected alternative.

The DesignTool has a central role in this framework. All the parts of the framework belong to each other directly or indirectly and thus establish mutual interaction.

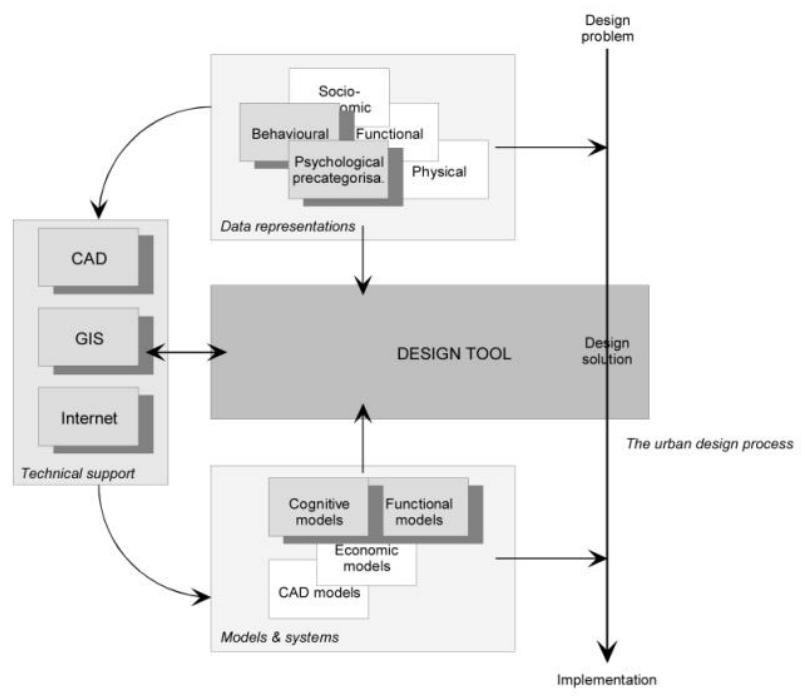

Figure 1: The framework of the implementation of computer technology in the urban design process according to a cognitive approach (based on Batty at al. [15])

\section{On cognitive science and computation}

In order to understand the knowledge on cognitive aspect of the urban environment, it is necessary to introduce the basic theory of cognitive vision.

In the process of architectural and urban design, the perception of the three-dimensional world constitutes the crucial knowledge and experience of space and its properties. Knowledge on how people perceive their environment and how they reproduce the related visual information is fundamental for understanding the process of cognitive mapping. The three-dimensional spatial perception indicates the way people perceive the space around them through vision. The theory of vision is focused on information processing; there are different approaches to how to reunite the whole picture emerged from the sequences during the motion and how to represent effectively the result of that process for the purpose of recognition.

Aspects of human vision, as well as the neuro-cognitive aspects, complemented by the theoretical postulates of computer vision are all part of the initial basis of this research.

The human vision system consists of a receptor system - the eyes, and a processor system the brain. David Marr [19] in his studies of vision and Bruce and Green [20] thoroughly investigated the functions of the human visual system. Vision is an information processing task that provides information about the shape and spatial relations of physical objects. "Vision is a process that produces from images of the external world a description that is useful to the viewer and not cluttered with irrelevant information" [19]. The process of reconstruction of two-dimensional retinal images is required to obtain a three-dimensional impression of the environment. It is obtained using available information in the retinal image.

An important part of this research is the understanding of 'high level vision or 'object recognition' derived from the work of Shimon Ullman [21] and his ideas about how the brain 'sees'. Knowledge about the process of classification of scene segmentations, visual routines, highlighted elements, as well as the work of neural mechanisms of the visual cortex which explains the functioning of the visual system are also significant and indispensible for the further research of the process of computer vision and computation.

These two theories, among others [22-24], were chosen since they strongly support the vision in the computational process required for this study. Marr's theory provides a starting point for developing a new model, while Ullman's theory provides an appropriate method to overcome the basic problems of object recognition and classification.

\section{Computer modeling in cognitive science}

Computation is the core concept of modern cognitive science. It is now a common place to use computers to model human cognition, which is again one of the starting points of artificial intelligence. Computation provides a general framework for the research of cognitive processes and behaviors. Thus, it is necessary to relate mathematical theory of computation, cognitive science and artificial intelligence, which are generally engaged in physical systems. Therefore, it is needed to establish a system that implements the relations between an abstract 
computer object and physical system. Implementation may have cognitive and thus, syntactic features as well. The physical system implements the given computation when the physical structure of the system is reflected as a formal structure of computation.

According to the type of mental traits, the main requirements of the cognitive model are: psychological - such as belief, learning and perception, and manifestational - those that are characterized by the way in which they are consciously perceived. Psychological characteristics are related to what makes the mind, while manifestation characteristics are related to the way they feel. However, the computer model is only a simulation. If the computer simulation is convenient, it will divide the informal system topology that is modeled so that the system is replicated rather than simulated. Some computer frameworks are able to explain and replicate human cognitive processes. Many researchers consider the implementation of computer models as an important test of its suitability for describing the internal mechanisms of human cognition. The reason for considering computer models suitable for cognitive models is that computerprocessed models need to be fully specified. Knowing that the model of human cognition is necessarily complex, there is a huge risk of inadequate specification of functions.

Testing the model by computer involves the creation of an appropriate test. The model generates the same results as the system it is created upon, which strongly supports the hypotheses that the model is made on the same principles as the basic system. When the model is constructed with the operation of human cognition, it is spatially huge, and thus should be optimized to the highest possible extent. Without additional restrictions, the correlation between the behavior of human cognition and some specific models cannot be used as a correct record of the model. In some cases, large models will replicate the behavior of the system at random.

Given the amount of information about human behavior and the spatial size of the model of intelligent systems, the verification of these models will require indefinitely long time. It is therefore essential to put more restrictions on the model space. Generally, models that are made for computers need to be completely specified. They are usually highly dynamic; every change in their functionality, such as learning through observation, is made with full action of the brain controlled by an external source. Thus, when the model is created for one action of human cognition, we intend to support the complex self-adaptive or selflearning systems.

The belief that simple models are probably correct for complex systems is based on the following two assumptions:

1) complex systems perform operations on a simple manner; and

2) there is a very small number of simple ways to perform operations.

The second assumption is reasonable while the first is not, especially for self-learning operations.

The possible advantage of simplification is in the reduction of the number of items, making thereby simple sequences more cost-effective. Simplicity is important because it enables the 'exterior designer' to evolve changes in the system much easier.

Before accepting it as a possible model of human cognition the following main conclusions can be applied to the operational aspect of the computer model:

1) that rather strict constraints are to be imposed on the possible model, significantly increasing its likelihood to be correct; and

2) that the model of self-learning operations cannot be simple, since its implementation is not simple as well.

The last possible conclusion is that it is difficult to find an applicable generic model for the operation of human cognition. However, computation is sufficiently flexible that it can cover almost all types of organizations, regardless that informal relations are conducted between low-level neural processes or high-level representations.

\section{Some observations on cognitive science and urban environment}

An urban environment can be highly complex. The structure of its representation in computer images is also complex and usually contains too much information to be effective in the process of recognition. The fundamental problem is how to organize this amount of information in an efficient manner for the given process of object recognition within the DesignTool.

There are three main prevailing theories on object recognition:

1) method of invariant properties leading to the representation of invariants, spatial characteristics, groupings and separation techniques;

2) method of decomposition of parts leading to representation of symbolic structural explanations, hierarchy of forms and syntactic pattern recognition; and

3) method of regulation, a trade-off method between variable separation of the observed 
object and the appropriate model (predefined and saved) and their comparison.

'The method of regulation', as defined by Ullman, is a 'more correct' method that can be applied to all possible circumstances. By the acceptance and integration of this method, the proper recognition of objects based on images taken from the urban environment is enabled.

According to the given tasks that DesignTool needs to resolve, and according to the cognitive approach and computation, a series of questions emerge that should be addressed properly. The basic question is: what information needs to be saved from one image to be used to design its adequate representation? Or, is it necessary to use all information from one image and have them all represented? Or more specifically, if the object is recognized from one image of the urban environment through the analysis of its forms and through the process of comparison, is it required to add the appropriate common attribute data to the subsequent computation process? These are several questions that reasonably emerge from this research context.

In conclusion, this paper suggests a new paradigm in the urban design practice, where the role of computer cognition is of crucial importance. The multidisciplinary research, whose theoretical framework is based on computer cognition aims to assist urban design professionals by the development of a new software tool called DesignTool. The purpose of the tool is to provide assistance in the analyses and verification of visual quality of the urban environment, as well as in the formation of alternative solutions, taken from the urban scenes based on their images. Due to achieve this objective, the research generates and integrates some of the methods and techniques for structuring and designing a new DesignTool. In addition to other applied sciences, the focus was also on the cognitive science, where two appropriate theories were elaborated for the object recognition system: Marr's 'computer vision' theory and Ullman's 'high-level' vision theory. Both theories allow theoretical and practical approach to human and computer vision. The paper presents the basic postulates of computer vision and cognitive perception from the aspect of urban environment, as the primary tasks of fundamental research concepts.

\section{References}

1. Barnett J. An introduction to urban design. Harper and Row Publisher Inc, 1982.

2. Sidjanin P. Visualisation of GIS Data in VR Related to Cognitive Mapping of Environment. Proceedings of the International Conference of Information Visualisation, London: England, 1998: 32. http://dx.doi.org/10.1109/iv.1998.694241

3. Sidjanin P. O primeni BIM tehnologije u graditeljstvu. Paper presented at the Fourth International Conference: Savremena teorija i praksa u graditeljstvu, Banja Luka, BiH, 2008.

4. Danahy J. Engaging Intuitive Visual Thinking in Urban Design Modelling, in P. Bancroft (Editor) ARCADIA: Workshop Proceedings, University of Michigan, Ann Arbor, MI, 1988: 87-97.

5. Decker J. Computers as tools for analysis of urban spaces. Cities. 1992; 9(3):170-176.

http://dx.doi.org/10.1016/0264-2751(92)90013-U

6. Shiffer MJ. Towards a collaborative planning system. Environment and Planning B: Planning and Design. 1992;19(6):709-722. http://dx.doi.org/10.1068/b190709

7. Ferreira J. Computing Technologies for Land Use and Regiona Planning at the National Capital Commission. Final Report Contract. 1993;91-02.

8. Dave B, Schmitt G. Information systems for urban analysis and design development. Environment and Planning B: Planning and Design. 1994;21(1):83-96.

http://dx.doi.org/10.1068/b210083

9. Al-Kodmany K. Bridging the gap between technical and local knowledge: Tools for promoting community-based planning and design. Journal of Architectural and Planning Research. 2001;18(2):110-30.

10. Talen E. Bottom-up GIS: A new tool for individual and group expression in participatory planning. Journal of the American Planning Association. 2000;66(3):279-94.

http://dx.doi.org/10.1080/01944360008976107

11. Harris B. Beyond geographical information systems: computers and the planning professional, Journal of the American Planning Association. 1989;55(1):85-92.

http://dx.doi.org/10.1080/01944368908975408

12. Denshman P. Spatial decision support systems. In D Maguire, M Goodchild, D Rhind (Eds.), Geographical Information Systems: Principles and Applications. Longman, 1991: 403-412.

13. 13 Klosterman R. Planning Support System: Integrating Geographic Information Systems, Models and Visualization Tools. Redlands, CA: Environmental Systems Research Institute and New Brunswick, NJ: Center for Urban Policy Research, 2001.

14. Schön DA. The reflective practitioner: how professionals think in action. Avebury: Alderschot, 1983.

15. Batty M, Dodge M, Jiang B, Smith A. GIS and Urban Design, London: UCL Centre for Advanced Spatial Analysis (CASA), 1998.

16. Parish $Y$, Mueller $P$. Procedural Modeling of Cities. Proceedings of ACM SIGGRAPH 2001 / COMPUTER GRAPHICS, Annual Conference Series, ACM Press. 2001: 301-308.

http://dx.doi.org/10.1145/383259.383292

17. Lynch K. The image of the city. MIT Press, 1960.

18. Sidjanin P. A Cognitive Framework for an Urban Environment Design Tool, Delft, TU-DKS, 2001.

19. Marr D. Vision New York: Freeman. 1982:31.

20. Bruce V, Green P. Visual perception: Physiology, psychology \& ecology. Erlbaum, Hillsdale, 1985.

21. Ullman S. High-level vision. MIT Press, 1996.

22. Cornou S, Dhome M, Sayd P. Architectural Reconstruction with Multiple Views and Geometric Constraints. Proceedings of British Machine Vision Conference, Norwick, UK, 2003.

23. Pizlo Z. 3D Shape - its unique place in visual perception. MIT Press, 2008.

24. Wilczkowiak M. 3D modelling from images using geometric constraints. PhD thesis, Institut National polytechnique de Grenoble, France, 2004 